\title{
CÓDIGOS IDENTIFICADORES DA REPRESENTAÇÃO DA ORALIDADE EM MAU TEMPO NO CANAL
}

\author{
Irene Maria Ferreira Blayer
}

\begin{abstract}
RESUMO: The most impressive trait of Vitorino Nemésio's oral style is the unifying linguistic indicators exhibited in the direct speech of his characters. In this literary attempt to mark the speaker's dialectal codes of speech, Nemésio seeks to construct a personality that stands apart, linguistically, from others in the text. In this essay, the literary representation of dialect in the discourse of one of the characters in Mau Tempo no Canal ${ }^{l}$ provides a background upon which the marked linguistic registers will be traced against existing linguistic data to form an expository analysis of the speech. The question is whether this oral fictional speech represents a truthful marker of Azorean linguistic identity. ${ }^{2}$
\end{abstract}

PALAVRAS-CHAVES: Mau Tempo no Canal, Vitorino Nemésio, oralidade, voz dialectal, idiolecto ficcional, identidade cultural.

É comum os romancistas recorrerem, nos seus romances, a recursos como distorção ortográfica, formações gramaticais alternativas, ou ao léxico duma particular região para exprimir ou representar as idiossincrasias verbais e fonéticas das suas personagens. Estas convenções, apresentadas sobretudo no âmbito dos diálogos, usam-se com a aparente intenção de conferir uma dimensão mais realista ou verídica ao discurso da diegese. Esta prática de estilo é vulgar em escritores como Dickens, Thomas Hardy, Emily Bronte, D. H. Lawrence, George Elliot, Mark Twain, entre outros, e, alguns exemplos desta convenção para distinguir os idiolectos das personagens nalguns dos romances destes escritores podem ilustrar-se mediante a ortografia de dey e dem por, respectivamente, they e them, para indicar um som sonoro; ou a designação ortográfica mouf e toff, por mouth e tooth, em que o $f$ substitui o som final não sonoro th (IVES, 1955, p. 88-96). Ao investigar os usos da linguagem não-padrão na literatura inglesa, Norman Page (1973, p. 54) faz eco desta maneira de resolver a caracterização dialectal mediante as técnicas convencionais adoptadas por certos escritores, e afirma: "Com base numa longa tradição, qualquer variante ortográfica pode interpretar-se como representando uma pronúncia não-padrão, até mesmo quando a ortografia, como nos casos de sez e tho', sejam tão-só toscas versões fonéticas da pronúncia padrão". Os escritores usam estas designações por razões fonéticas e como códigos de variação regional para identificar personagens que se exprimem num dialecto. $\mathrm{Na}$ verdade, a representação literaria do dialecto é potencialmente uma importante fonte de evidência no que concerne aos registos de oralidade na sua manifestação ficcional.

Entre escritores portugueses de nota do século XX que recorrem à representação do discurso ficcional para ilustrar um registo linguístico das suas pesonagens, conta-se Vitorino Nemésio. Os leitores

Doutorada pela Universidade de Toronto, Canadá (1992), é professora catedrática no Departamento de Línguas, Literaturas e Culturas Modernas na Universidade de Brock, Canadá. Ao seu principal campo de pesquisa - os estudos linguísticos num contexto histórico -, alia-se um segundo campo de investigação, a tradição narrativa oral e sua importância relativamente aos conceitos de identidade e cultura. Das suas publicações mais recentes destacam-se vários livros, ensaios editados em revistas internacionais especializadas, e capítulos em livros académicos. Além de conferências e trabalhos apresentados em congressos nacionais e internacionais, é membro de várias associações académicas, comités universitários, e integra a comi ssão científica de várias revistas. Foi eleita ao Senado da Universidade (2001-05) e reeleita em 2006 (a 2009); e nomeada para o "Governance Committee", em 2006.

1 Todas as referências serão da edição que estou a usar de Mau Tempo no Canal, Obras Completas de Vitorino Nemésio. [Introdução de José Martins Garcia] Lisboa: Imprensa Nacional-Casa da Moeda, 1999. v.VIII.

${ }^{2}$ Apresenta-se uma versão destas ideias no ensaio "Literary Representation of Non-Standardness as a Marker of Dialect 'Voice' in Mau Tempo no Canal: Some Considerations" Portuguese Literary and Cultural Studies, Vol. 11 (no prelo). 
familiarizados com a obra de Nemésio descobrem que o interesse do Autor pelos falares açorianos está assinalado na sua ficção, sobretudo mediante o uso extensivo dum vocabulario especializado atribuído a algumas das suas personagens. De longe o mais impressionante "estilo oral" nemesiano, a que o Autor recorre como recurso unificador patente no discurso directo das personagens, é a representação de características fonéticas do discurso idiolectal. Nemésio distorce e manipula a ortografia para enfatizar determinadas características cujo objectivo é fazer sobressair aspectos da pronúncia. Estes aspectos são representados ortograficamente, com pormenores suficientes para destacar o seu carácter não-padrão, de modo a captar pronúncias regionais (dos Açores). O Autor consegue fazê-lo explorando e exagerando os recursos literários de dialecto visual ${ }^{3}$ e ortografia no discurso directo das personagens. Através das técnicas da representação literária do discurso humano, os protagonistas como Amaro de Mirateca, o pescador/baleeiro de Mau Tempo no Canal, integram, na diegese do romance, a 'dimensão oral' .

Consequentemente, na identificação das personagens do povo, a oralidade constitui um aspecto preponderante de Mau Tempo no Canal ${ }^{4}$. A passagem seguinte servir-nos-á de ilustração de algumas das técnicas a que Nemésio recorre na representação do discurso oral:

...Chomei o mê Lauriano e santei-o aqui im riba dos joêlhos, co lincinho dêle puinduirado na mão: "Toma lá, meu home! Andas sempre co êsse ranho a caiir..." "Olha, olha, meu avô! o qu'o Menino Jasus me troixe!...” E tira dobaixo do braço ũa canoinha de buxo, cum giga, moitães, e o sê poparo todo!

Foi o pai que la fez co a navalha... Andou co aquilho inscundido na manta, somanas a fio...! Só qu'ria qu'a menina visse! Parcia mesmo ũa imbarcação deveras, a saiir o Canal de vento à popa... ("Oceano Glacial Ártico", p. 252)

A ortografia não-padronizada é uma tentativa de representação fonética duma forma variante do discurso, por exemplo: chomei (chamei), me (meu), santei-o (sentei-o), lincinho (lencinho), puinduirado (pendurado), home (homem), Jasus (Jesus). Os marcadores de oralidade linguística estão claramente indiciados no idiolecto da personagem. Torna-se assim bastante evidente ao leitor atento aos diálogos ficcionais nemesianos, e particularmente ao leitor que os lê em voz alta, que este discurso é uma característica fundamental da performance da personagem, em termos choamskianos, análogos, em Saussure, ao conceito parole. O Autor fornece-nos informação suficiente para produzir um distinto "efeito dialectal" . Assim, Nemésio expõe o leitor a uma dimensão acústica no discurso da personagem que resulta num entrecruzamento de vozes linguísticas intimamente relacionadas com a estratificação social e o regionalismo. Dadas as ocorrências destas caraterísticas na obra de Vitorino Nemésio, a questão - do ponto de vista da leitura fonológica do texto - está relacionada com a interpretação: Que significado devemos atribuir aos padrões discursivos representados no romance? Para entrar mais a fundo nesta questão, será necessário estabelecer uma base a partir da qual possamos analisar qualquer variação linguística. Sumner Ives (1950, p. 137-182) fornece-nos uma útil discussão das teorias e aplicações linguísticas que presidem à representação literária dos dialectos.

Em reacção ao artigo-chave de Ives, tem-se dado como facto adquirido que, para uma leitura cabal dum dialecto literário, é necessário sabermos em primeiro lugar o dialecto do próprio Autor e depois ajuizar do(s) dialecto(s) da(s) sua(s) personagem(ns) em relação ao do seu criador. É mediante a sua própria construção verbal que o Autor constrói a representação idiolectal ou o discurso oral. O trabalho de Ives presume, no entanto, que "Quando um autor usa um dialecto como veículo literário... aquilo que ele está a usar é uma série de usos típicos - um tipo de koine. Do total de material linguístico ao seu dispor, ele selecciona aquelas características que lhe parecem típicas... ao tipo de indivíduo que está a ser representado" (IVES, 1950, p. 144). No caso de Nemésio, podemos dar como assente o seu interesse por uma literatura regional e que, por isso mesmo, a relação entre o discurso e dialecto ficcional e a representação dos falares açorianos é uma constante da sua obra. A propósito, cito uma afirmação de Nemésio feita numa entrevista bastante no início da sua carreira:

Não temos literatura propriamente açoreana porque os nossos poetas e escritores estão fora da alma açoreana. A língua com que trabalham a prosa e o verso é uma língua cujos vocábulos vêm nos dicionários mas que não trazem a comoção do nosso povo. $\mathrm{O}$ nosso povo tem uma sintaxe $\mathrm{e}$ expressões próprias. Ora os poetas e escritores açoreanos não escrevem com o sentido regional do

\footnotetext{
${ }^{3}$ Paul H. Bowdre, "Eye Dialect as a Literary Device in the Works of Sidney Lanier," in Shores and Hines (1977): 247-251.

${ }^{4}$ Sobre aspectos da oralidade no romance, veja-se Francisco Cota Fagundes. "Dos vários registos de oralidade em Mau tempo no Canal: estórias de mulheres" (no prelo).

${ }^{5}$ Em cursiva para alertar o leitor à variação dialectal.

${ }^{6}$ Definições de 'dialecto' e 'linguagem’ em John Lyons, Language and Linguistics. (Cambridge: Cambridge University Press, 1982, p. 26). Peter Trudgill, Accent, Dialect and the School (London: Arnold, 1975); T. A. Sebeok, Style in Language (Mass.: MIT Press, 1960); D. Abercrombie, Problems and Principles in Language Study (London: Oxford University Press, 1967); Uriel Weinreich, "Is Structural Dialectology Possible?" Word, X, 1954, p. 388-400.
} 
vocábulo, com a sintaxe e a expressão populares. Dentro de um livro de versos de qualquer poeta pode haver poesia, mas o povo, o nosso povo, não está dentro dele. ${ }^{7}$

Se Mau Tempo no Canal é a expressão máxima da "açorianidade", a questão que se coloca é se o discurso ficcional das personagens no romance também reflecte fiel e objectivamente as idiossincrasias linguísticas do falar da comunidade regional insular; ou seja, se este discurso oral fictício representa um indiciador de identidade linguística local, um testemunho de "açorianidade".

Em casos em que (ao referirmo-nos a características do discurso das personagens e/ou à subjacente variante linguística e à caracterização do idiolecto) haja a pressuposição dum dialecto, a representação escrita de "variante linguística" a que um romancista recorre pode comunicar significados distintos a distintos leitores, particularmente em casos em que o leitor não esteja familiarizado com esse falar regional. Assim, parece muito provável que, como nos indica Page (1973, p. 52), "o autor que use termos dialectais ou indicadores de pronúncias regionais corre o risco de mistificar o leitor". Esta afirmação é particularmente relevante para a leitura do uso que faz Nemésio do dialecto no seu diálogo ficcional.

No que respeita aos trabalhos de Nemésio e, em particular, com relação ao uso de dialecto literário, a crítica tem prestado pouca atenção a um dos importantes recursos da sua linguagem ficcional. Algumas das tentativas mais sucintas de relacionar o "estilo oral" de Vitorino Nemésio a recursos linguísticos específicos usados no seu discurso literário devem-se a Martins Garcia (1978), Heraldo da Silva (1985), Machado Pires (1998) e a Mateus Silva (1994) ${ }^{9}$. Em geral, estes estudiosos descrevem elementos essenciais no sistema de estilo oral de Nemésio, ao mesmo tempo em que levantam alguns problema em relação a eles. Martins Garcia (1978, p. 137-138), por exemplo, sugere que

Vitorino Nemésio debateu-se com o intricado problema de reproduzir foneticamente o falar de certas regiões dos Açores. Poderemos afirmar que, em alguns casos, conseguiu resultados aproximativos [...] Por outro lado, a variante dialectal que Nemésio nos apresenta pertence a qual das ilhas dos Açores? Um exemplo: mãis, em vez de mas, conjunção adversativa. Existe na Terceira? Acredito, tal a frequência com que ocorre em o Mistério do Paço do Milhafre. Quando porém, ti' Amaro da [sic] Mirateca (baleeiro do Pico) relata as suas aventuras (Маи Тempo no Canal), lá está a conjunção mãis - coisa que os meus ouvidos de picaroto nunca tal ouviram in loco. O mesmo direi de oitro (variante de outro) que não me consta existir no Pico.

A implicação destas palavras é que, como indica o crítico, "Vitorino Nemésio, por exemplo quis reproduzir, como verossimilhança fonética (mas que na página tem de servir da grafia - eis o drama!) as características específicas da realização fónica regional” (Martins Garcia, 1978, p. 136). E acrescenta:

A tentação foneticista está pois num beco sem saída: ou é fiel à sequência fónica (na sua oralidade) e então teria de grafar-se segundo um alfabeto fonético, ou rejeitando o alfabeto fonético (que é o que acontece de facto), utiliza, o alfabeto corrente... e passa a flutuar no gráfico, sem critério aceitável. (Martins Garcia, 1978, p. 162)

Um dos propósitos da representação gráfica do dialecto regional é criar um tecido de coesão e plausibilidade linguística que se deve encarar como sendo um reflexo imediato do "verdadeiro" discurso da personagem, ou seja, um indiciador da oralidade. Contudo, ao apontar para um "drama" ou "um beco sem saída" no que respeita à representação do discurso, Martins Garcia já está a sugerir que este tipo de texto representa e reflecte uma precária e problemática realidade linguística. De importância crucial para nós é que o discurso escrito - gravado ou ficcional - fornece amplas possibilidades de registar características linguísticas a serem identificadas e aplicadas a um grupo social e regional, ou simplesmente a um idiolecto idiossincrático. Como nos indica Norman Page (1973, p. 96), "até mesmo o discurso regional mais realista geralmente representa uma considerável selecção e convencionalização da

\footnotetext{
7 "Por que não temos literatura açoriana? Entrevista com Vitorino Nemésio, por Rebelo de Bettencourt", Diário dos Açores a 2 de Maio de 1923, também publicado em A Questão da Literatura Açoriana: Recolha de Intervenções e Revisitação, org. por Onésimo Teotónio Almeida (Angra do Heroísmo: Secretaria Regional de Educação e Cultura, 1983): 27-31.

${ }^{8}$ Sobre a 'açorianidade', veja-se: Onésimo T. Almeida, ed., A Questão da Literatura Açoriana: Recolha de Intervenções e Revisitação (Angra do Heró́smo: Secretaria Regional de Educação e Cultura, 1983): 27-31; ibid., Açores, açorianos, açorianidade: um espaço cultural (Lisboa: Signo, 1989); Hearaldo G. Da Silva, Açorianidade na prosa de Vitorino Nemésio: realidade, poesia e mito (Lisboa: Co-edição Imprensa Nacional-Casa da Moeda/Secretaria Regional de Educação e Cultura Região Autónoma dos Açores, 1984); Luís da Silva Ribeiro, "Subsídios para um ensaio sobre a açorianidade"; rtp Obras Completas II. História (Angra do Heroísmo: Instituto Histórico da Ilha Terceira / Secretaria Regional de Educação e Cultura Região Autónoma dos Açores, 1983): 515-56; Adelaide Batista, João de Melo e a Literatura Açoriana (Ponta Delgada: D. Quixote, 1993); José Martins Garcia, Para uma literatura Açoriana (Ponta Delgada: Universidadedos Açores, 1987); Vamberto Freitas, O Imaginário dos Escritores Açorianos (Lisboa: Salamandra, 1992).

9 José Martins Garcia, "A Linguagem do Narrador," in Vitorino Nemésio - a obra e o homem (Lisboa: Arcadia, 1978). Heraldo da Silva "O Português Oral dos Açores na Prosa de Vitorino Nemésio," Arquipélago, VIII:1 (1985): 141-62; Helena Mateus Silva, "A presença do linguísta no Mau Tempo no Canal,” in Insulana, V: 1 (Ponta Delgada, 1994); A. M. Machado Pires, "Língua e Criação Literária em Vitorino Nemésio," in Vitorino Nemésio, Rouxinol Mocho (Praia da Vitória: Câmara Municipal, 1998): 45-56.
} 
verdadeira língua das pessoas”. Se esta observação é aplicável a Nemésio, até que ponto serão válidas as atribuições que lhe têm sido feitas com respeito à representação, no romance, do discurso dialectal? Sem recorrer pormenorizadamente às exemplificações, não nos será possível entrar nos numerosos e complexos aspectos de "mediação" entre o discurso ficcional representado e as características linguísticas comuns aos que partilham a mesma herança dialectal. Mesmo assim, o que se pretende identificar, se possível, são as características do discurso directo que registam códigos linguísticos de um falar regional açoriano.

Como se sabe, segundo os códigos linguísticos seleccionados por Nemésio, algumas personagens evidenciam em discurso directo um idiolecto com características regionais distintas da língua padrão ${ }^{10}$. No Capítulo XXVIII, “Oceano Glacial Ártico," de Mau Tempo no Canal, o discurso "oral” de Tio Amaro de Mirateca, o pescador/baleeiro, regista suficientes deviações coloquiais da língua padrão, assim como usos e formas linguísticas distintas das demais personagens ficcionais. Mirateca, o conversational storyteller $^{11}$ domina o espaço dialógico neste capítulo, e a sua voz enquadra-se na representativa fala de uma comunidade socio-linguisticamente distinta. Neste discurso ${ }^{12}$, ele é o controlador consciente da sua própria estória; as estórias de Nemésio, narradas num registo oral que contrasta com o das outras personagens deste capítulo: Margarida e o seu pai, Diogo Dulmo, cuja linguagem pertence à hierarquia social representativa da norma linguística padronizada. As divergências linguísticas são distintas entre estas personagens, e as diferenças sociais se salientam na representação da oralidade, como a própria voz do narrador nos informa: "Margarida, quase sem dar por isso não sabia falar com gente desta senão na língua comum”(Mau Tempo no Canal, p. 251).

Eis o extracto que inicia o diálogo do capítulo e que nos servirá como testemunho de oralidade representativa do povo, na voz do baleeiro, Amaro de Mirateca:

Vossa Sinhoria intende? Mulheres da vida... rapazes novos... Inda tinha tabaco no imbigo: sei lá!... quinz(i) anos, é o qu'ê podia ter. Mãis lá me curei... - E, vendo Margarida que descia o resto da escada, de costas, à marinheira, o ti Amaro curvou-se ao ouvido de Roberto: - (O nosso midship, o Bob, o tal de Nantaque, é que me amezinhava e m'espremia; fazia-me essa caridade...). Isto é d'ũa pérola d'ũa menina! Tamém vem oivir o velho?... Pois era... 'Tava aqui a dezer ò sê tio e ò papai que cumecei a balear munto antes das sortes... aiinda botava o mê pião lá $\square$ ua vez por oitra. Só qu'ria ũa pataca por cada vez que mê pai me puxou pola ponta da fieira qu'ê deixava caiir aqui im riba da fralda, na pressa de m'iscunder... Ficava mai' rico qu'ò sr. Altre Bensaúde! Aquilho é qu'era tempo! e um rospeito...! Qũem pertindia a ũa cumpanha pidia a be nça [sic] ò mestre, coma hoij'im dia só se pede a pai e a mãe... q'ando é!

"Tinho apanhado po'ju'tiça um brigue francês qu'andava aí perto da costa, à baleia e ò peixe de caldo. Parece que o stou vendo...: rabeiro, alto de proa...: o Denis. O guarda a dezer: "Haija quem mai' lance!" ... e um home brabado qu'aí havia, a picar... a picar... Os oitros bem se chegavo!: êl cobria semp'e. ("Oceano Glacial Ártico", p. 247)

\footnotetext{
${ }^{10}$ Veja-se entre outros os seguintes estudos sobre o Português dos Açores: Maria de Fátima Freitas Baptista, "Ilha do Faial (Açores): Contribuição para o estudo da sua linguagem, etnografia e folclore" (Coimbra, 1970); Irene Maria F. Blayer, "Aspects of the Vocalic System in the Speech of the Azores Islands," Ph.D. Diss., University of Toronto (1992); Manuel de Paiva Boléo. "A Língua Portuguesa do Continente, dos Açores e do Brasil (Problemas de Colonização e Povoamento)," Revista Portuguesa de Filologia, 18 (1983): 591-625; Nair Odette da Câmara Borges, Influência anglo-americana no falar da ilha de S. Miguel (Açores), RPF, Suplement II (Coimbra, 1960); Maria Alice Borba Dias, "Ilha Terceira: Estudos de linguagem e etnografia" (Lisboa, 1965); José Leite de Vasconcelos, "Dialectos Açoreanos (Contribuição para o estudo da Dialectologia Portuguesa)," Revista Lusitana, 2 (189092): 289-307; Maria Lúcia Borba Maia, "O falar da ilha Terceira" (Lisboa, 1965); Lygia Maria da Câmara Almeida Matos, Ilha de S. Miguel, seu dialecto e literatura popular (Ponta Delgada, 1936); Maria de Jesus C. Medeiros, "A linguagem micaelense em alguns dos seus aspectos" (Lisboa, 1964); Elsa de Mendonça, "Ilha de São Jorge: Subsídio para o estudo da etnografia, linguagem e folclore regionais" (Lisboa, 1959); José de Almeida Pavão, Aspectos populares micaelenses, $2^{\text {nd }}$ ed. (Angra do Heroísmo: Secretaria Regional da Educação e Cultura, 1981); as well as Aspectos do Cancioneiro Popular Açoriano (Ponta Delgada: Universidade dos Açores, 1981); Luís da Silva Ribeiro, "Formação do Povo dos Açores: Subsídio para o seu estudo," Obras II, Historia (Angra do Heroísmo: Instituto Histórico da Ilha Terceira, Secretaria Regional da Educação e Cultura, 1983): 45-68; Francis Millet Rogers, "The Pronunciation of the Madeira and Azores Dialects as Compared with Standard Portuguese," Doctoral Diss., Harvard, 1940; ibid., "Insular Portuguese Pronunciation: Madeira," Hispanic Review, XIV (1946): 235-253; ibid., "Insular Portuguese Pronunciation: Alleged Flemish Influence." Mediaeval Studies in Honor of J. D. M. Ford, Ed. U. T. Holmes and A. J. Denomy (Cambridge: Harvard University Press, 1948); ibid., "Insular Portuguese Pronunciation: Porto Santo and Eastern Azores," Hispanic Review, XVI (1948): 1-32; ibid., "Insular Portuguese Pronunciation: Alleged Breton Inluence," Romance Philology II (1949): 305314; ibid., "Insular Portuguese Pronunciation: Central and Western Azores," Hispanic Review, XVII (1949): 1-32; João das Pedras Saramago, "A ilha do Corvo, alguns dos seus aspectos linguísticos" (Lisboa, 1987); assim como Le parler de l'île de Corvo Açores, Diss., Grenoble, Université Stendhal, 1992; David J. Silva, "Vowel Shifting as a Marker of Social Identity in the Portuguese Dialect of Nordeste, São Miguel (Azores), "Luso-Brazilian Review, 42:1(2005):1-20; ibid., "The variable deletion of unstressed vowels in Faialense Portuguese," Language Variation and Change, 9 (1997): 295-308.

${ }^{11}$ Neal R. Norrick. Conversational; Narrative: Storytelling in Everyday Talk (John Benjamins: Amsterdam, 2000).

${ }^{12}$ D. Schiffrin. Discourse Markers (Cambridge UK: Cambridge UP, 1987).
} 
São abundantes, neste capítulo, os exemplos de características fonéticas que distinguem o idiolecto de Mirateca das demais personagens. A sua fala tem interesse sociolínguistico na identificação de um plano de oralidade linguística do romance, e entre os traços fonéticos mais proeminentes destaca-se a variação vocálica tanto das pretónicas como tónicas nasais e orais.

Quadro 1

\begin{tabular}{lll}
\hline Vogais tónicas (nasais) & Variante & Ortografia Padrão \\
\hline$/ \tilde{\mathrm{a}} />[\tilde{\mathrm{e}}]$ & $\underline{\text { entes, diente }}$ & antes, diante \\
$/ \mathrm{e} />[\tilde{a}]$ & assantou, santei & assentou, sentei \\
\hline
\end{tabular}

Quadro 2

\begin{tabular}{|c|c|c|}
\hline Vogais átonas & Ortografia Variante & Ortografia Padrão \\
\hline$/ \mathrm{e} />[\mathrm{i}]$ & 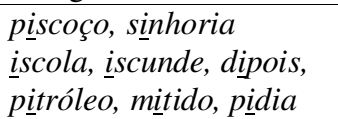 & $\begin{array}{l}\text { pescoço, senhoria } \\
\text { escola, esconder, depois } \\
\text { petróleo, metido, pedia }\end{array}$ \\
\hline$/ \mathrm{a} />[\mathrm{e}]$ & rezzão & razão \\
\hline$/ \mathrm{i} />[\mathrm{e}]$ & $\overline{d e} z e$ & dizer, \\
\hline /i/ $>[\mathrm{o}]$ & promeira & primeira \\
\hline$/ \mathrm{e} />[\mathrm{o}]$ & lovei, lovava, somanas & levei, levava, semanas \\
\hline$/ \mathrm{o} />[\mathrm{u}]$ & cümecei $\bar{i}$ & comecei \\
\hline$/ \tilde{\mathrm{e}} />$ [1] $]$ & $\begin{array}{l}\text { introixar, intende, infim } \\
\text { lincinhos, pertindia }\end{array}$ & $\begin{array}{l}\text { entrouxar, entende, enfim } \\
\text { lencinhos, pretendia }\end{array}$ \\
\hline$/ \tilde{\mathrm{o}} />[\tilde{\mathrm{u}}]$ & $\begin{array}{l}\text { cümparando, cumpanha } \\
\text { cuntar, fruntal }\end{array}$ & $\begin{array}{l}\text { comparando, companha } \\
\text { contar, frontal }\end{array}$ \\
\hline$/ \tilde{\mathrm{e}} />[\tilde{\mathrm{a}}]$ & antão, Bansaúde & então, (mas também atão), Bensaúde \\
\hline$/ \tilde{\mathrm{u}} />[\tilde{1}]$ & imbigo & Umbigo \\
\hline
\end{tabular}

Casos de redução do ditongo decrescente (átono ou tónico) é outra característica deste idiolecto. Alguns exemplos:

Quadro 3

\begin{tabular}{|c|c|c|}
\hline Monotongação & Variante & Padrão \\
\hline$/ \mathrm{eu} />[\mathrm{e}]$ & 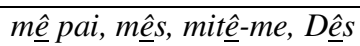 & meu pai, meus, meteu-me, Deus te guie \\
\hline$/ \tilde{a} \tilde{u} />[\tilde{a}]$ & $n \underline{\tilde{a}}$ & não dou, não passava \\
\hline /ãũ/ > [a] & bença & benção (com desnasalização) \\
\hline
\end{tabular}

Há consistência no uso do ditongo /oi/ por [ou] em casos que, por exemplo, o [ou] reflecte a pronúnica padrão: oitro, oivir, contudo sem alteração em ouvido. Existe repetição frequente de um som vocálico para indicar o distinto efeito articulatório da vogal: aịnda, caiịr para ainda e cair, respectivamente. Nota-se a frequente perda de sons tanto vocálicos como consonânticos, em particular, muitos casos de síncope, por exemplo: mai'rico (mais rico), qu'ria (queria), m'espremia (me espremia), semp'e (sempre), home'brabado (homem barbado); ou aférese: 'inda (ainda), 'tava (estava), 'stou (estou). A metátese é esporádica mas para exemplos sistemáticos de permutação histórica temos /pre/ > /per/: pertindia < pretendia. Neste trecho evoca-se a oralidade na representação consciente de alguns vocábulos que registam formas arcaicas e/ou coloquiais. Isto acontece, por exemplo, em ũa ua (uma), mũto / munto (muito), mãis (mais), ó (ao), haija (haja), entre outros; ou no uso de termos marcadamente regionais: inté (até); qu'inté (que até). Há também a tendência de inserção, ou prótese: alambrança (lembrança). Do mesmo modo, são comuns na fala popular e detectados no idiolecto de Mirateca os termos mãis (mas), mum (muito), n’ũa (numa), quinhães (quinhões), ou seja, usos não aceites na linguagem educada. Há vacilação na pronúnca de certos vocábulos tais como: aquilo // aquilho, atão // antão (então), sempre // semp'e. Alguns exemplos de formação anti-hiática pertinentes neste idiolecto: prà nossa (i) arte; a gente équ'insinou a (i) arte; parcia (i) áugua; uma característica da fala do grupo central, em particular da ilha Terceira (BLAYER, 1992).

Ao enquadrar o discurso da personagem no contexto linguístico da "fala açoriana" (BLAYER 1992), a minha intenção era detectar o que nessa fala remetia para o que acredito ser evidência objectiva e natural (Saussure). Nesta breve introducção, a voz de Mirateca atravessa o discurso narrativo da sua estória e sobressai na representação dialectal da oralidade. Este estilo de expressão linguística foi cuidadosamente seleccionado pelo Autor a fim de estabelecer relação com as respectivas tendências orais e proporcionar variantes não-padronizadas. Pelo discurso da diegese no Capítulo XXVIII repetem-se fenómenos linguísticos correspondentes aos registados na passagem introductória; mas são as variações 
vocálicas os traços mais salientes do idiolecto de Mirateca. Existe uma correlação linguística directa entre o idiolecto ficcional nemesiano - a voz de Mirateca - e a do falante insular que exibe estas variações dialectais. Neste discurso estas variações correspondem às de uma comunidade insular cujas modulações de oralidade são atribuíveis, sociolinguisticamente, a estes paradigmas regionais.

$\mathrm{Na}$ análise do discurso de Mirateca, é evidente que o dialecto literário de Nemésio resulta eficaz tanto como recurso literário como um elo entre a linguagem, a cultura e a história. Na linguagem das "estórias" de Mirateca, a fala açoriana converte-se num microcosmo dum mundo homogeneizante, demarcando assim não só as fronteiras entre falantes de dialectos mas também as suas identidades sociais e culturais. O leitor pode ter a sensação de que o Autor criou um mundo linguístico que directamente reflecte as suas próprias experiências destinadas a apresentar um retrato dum património linguístico sociocultural. Para efectuar a sua meticulosa construção destas personalidades literárias, Nemésio enfatiza o estilo oral na sua ficção como tentativa de representação de divergências regionais e sociais no respeitante à pronúncia. Ele codifica a sua perceptual dialectologia ficcional e enriquece o discurso das suas personagens literárias, mediante a exploração e exageração dos recursos literários como o dialecto visual, ao mesmo tempo em que marca ou particulariza os códigos dialectais do discurso da personagem. Nemésio estabelece, assim, uma voz literária única, a qual é identificável pelos seus desvios do português padrão no que respeita ao léxico, à pronúncia e a estruturas gramaticais, ao mesmo tempo que justapõe elementos linguísticos estranhos a qualquer leitor não familiarizado com o património linguístico, ou padrões linguísticos, dos Açores. O dialecto literário, porém, deve possuir relevância para além da correcção das representações autorais do falar local, e Vitorino Nemésio consegue-o através da oralidade representativa da "açorianidade".

Abordo estes conceitos com a consciência de que, para Nemésio, o dialecto literário era uma componente importante na confecção das suas estórias. A personagem de Amaro de Mirateca testemunha que, na representação dialectal nemesiana, o Autor procura construir personalidades que linguística - e também cultural e socialmente - se destacam das demais personagens que configuram o texto, e, cuja performance se reconcilia com tradições açorianas de narrativa oral, ao mesmo tempo em que reflecte parâmetros açorianos de marcadores da identidade social, cultural e linguística.

\section{BIBLIOGRAFIA}

BAKHTIN, Mikhail. The Dialogic Imagination. [Ed. Michael Holquist, trans. by Caryl Emerson and Michael Holquist] Austin: University of Texas Press, 1981.

BLAYER, Irene Maria F., \& Mark Anderson, eds. Latin American Narratives andCultural Identity: Selected Readings. New York, Bern, Oxford: Peter Lang, 2004.

BLAYER, Irene Maria F.; SANCHEZ, Monica (eds). Storytelling: Interdisciplinary \& Intercultural Perspectives. New York, Bern, Oxford: Peter Lang, 2002.

BURTON, Deirdre. Dialogue and Discourse. London: Routledge \& Kegan Paul, 1980.

CHAFE, Wallace. Discourse, Consciousness, and Time. Chicago: University of Chicago Press, 1994.

CHATMAN, S. Story and Discourse. Ithaca: Cornell University Press, 1978.

CLARK, Kate. The linguistics of blame. In: Language, Text and Context. Ed. Michael Toolan. London: Routledge, 1992. p. 208-224.

COULTHARD, Carmen R.; COULTHARD, Malcolm (eds). Texts and Practices: Readings in Critical Discourse Analysis. London: Routledge, 1996.

CULLER, Jonathan. Jakobson and the Linguistic Analysis of Literary Texts. In: Language and Style, n.5, 1971. p. 53-66.

CULLER, Jonathan. On Deconstruction. London: Routledge \& Kegan Paul, 1983.

FAGUNDES, Francisco Cota. Traduzindo Mau Tempo no Canal para o inglês: Stormy Isles: An Azorian Tale. In: Vitorino Nemésio Vinte Anos Depois. Seminário Internacional de Estudos Nemesianos. [Ed. António Manuel Machado Pires et alii] Lisboa: Cosmos, 1998. p. 342-376.

FAIRLOUGH, Norman. Critical Discourse Analysis. London: Longman, 1995.

GUMPERZ, J. Language and Social Identity. Cambridge: Cambridge University Press, 1982.

HYMES, Del. Models of the Interaction of Language and Social Life. In: Directions in Sociolinguistics. [Eds. J.J. Gumperz and Del Hymes] New York: Holt, Rinehart \& Winston, 1972.

IVES, Sumner. A Theory of Literary Dialect. In: Tulane Studies in English, n.2, 1950, p. 137-182. 
IVES, Sumner. Dialect Differentiation in the Stories of Joel Chandler. American Literature, n. 17, p. 8896, mar. 1955.

JAKOBSON, Roman. Closing Statement: Linguistics and Poetics. In: Style in Language. [Ed. Thomas Sebeok] Cambridge, MA: MIT Press, 1960. p. 350-377.

JAWORSKI, Adam, and Nikolas Coupland. The Discourse Reader. London: Routledge, 1999.

NEMÉSIO, Vitorino. Mau Tempo no Canal. In: Obras Completas de Vitorino Nemésio. [Introdução de José Martins Garcia] Lisboa: Imprensa Nacional-Casa da Moeda, 1994. v.VIII.

NEMÉSIO, Vitorino. O Açoriano e os Açores. In: Sob os Signos de Agora, Obras Completas de Vitorino Nemésio. Lisboa: Imprensa Nacional-Casa da Moeda, 1977. v.XIII. p. 97.

NEMÉSIO, Vitorino. Stormy Isles: An Azorean Tale. [Edited, translated, annotated and with an introduction by Francisco Cota Fagundes]. Providence: Gávea-Brown, 1998.

PAGE, Norman. Speech in the English Novel. London: Longman, 1973.

TANNEN, Deborah. Talking Voices. Repetition, Dialogue and Imagery in Conversational Discourse. Cambridge: Cambridge University Press, 1990. v.6.

TODOROV, Tzevan. Les Registres de la parole. Journal de Psychologie, n.64, 1967, p. 265-278.

TOOLAN, M. Analysing Fictional Dialogue. Language and Communication, n.5, v.3, 1985, p. 193-206.

TOOLAN, M. Conversation in Fiction. Poetics Today, n. 8, 1987, p. 393-416. 